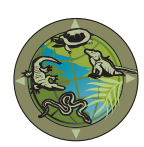

\title{
Overwintering Observations of Northern Leopard Frog (Lithobates pipiens) Activity under Ice
}

\author{
Natasha Kreitals ${ }^{1,2}$, John-Mark Davies ${ }^{3}$, Dave W. Phillips ${ }^{4}$, and Iain D. Phillips ${ }^{1,2,3}$ \\ ${ }^{1}$ TRoutreach Saskatchewan, Saskatchewan Wildlife Federation, 9 Lancaster Drive, Moose Jaw, Saskatchewan S6J 1M8, Canada \\ ${ }^{2}$ Department of Biology, University of Saskatchewan, Saskatoon, Saskatchewan S7N 5E2, Canada \\ ${ }^{3}$ Water Quality and Habitat Assessment Services, Water Security Agency of Saskatchewan, Saskatoon, Saskatchewan S7N 3R3, Canada \\ ${ }^{4}$ Frogworks, Box 802, Lumsden, Saskatchewan S0G 3C0, Canada \\ Corresponding author: Iain D. Phillips (iain.phillips@wsask.ca)
}

$\mathrm{B}_{\mathrm{H}}^{\mathrm{i}}$ iodiversity loss among amphibians is global in scope. From a broad perspective, climate change, habitat disruption, exotic compounds, and weather patterns affect frog species and populations (Drost and Fellers 1996, Pope et al. 2000, Sparling et al. 2001, Pounds et al. 2006). Understanding such losses within a local context-dependent perspective is important for conservation purposes (Blaustein and Kiesecker 2002). In Canada, the Northern Leopard Frog (Lithobates pipiens, formally Rana pipiens; Screver 1782) was once widespread, but has now vanished or declined in much of its western range (Kendell 2000). As a result it has been listed under Schedule 1 of the Species at Risk Act (SARA) and by the Committee on the Status of Endangered Wildlife in Canada as being of "special concern" (Environment Canada 2013). One of the main issues in developing a management plan for the species has been the lack of data on abundance measures and little

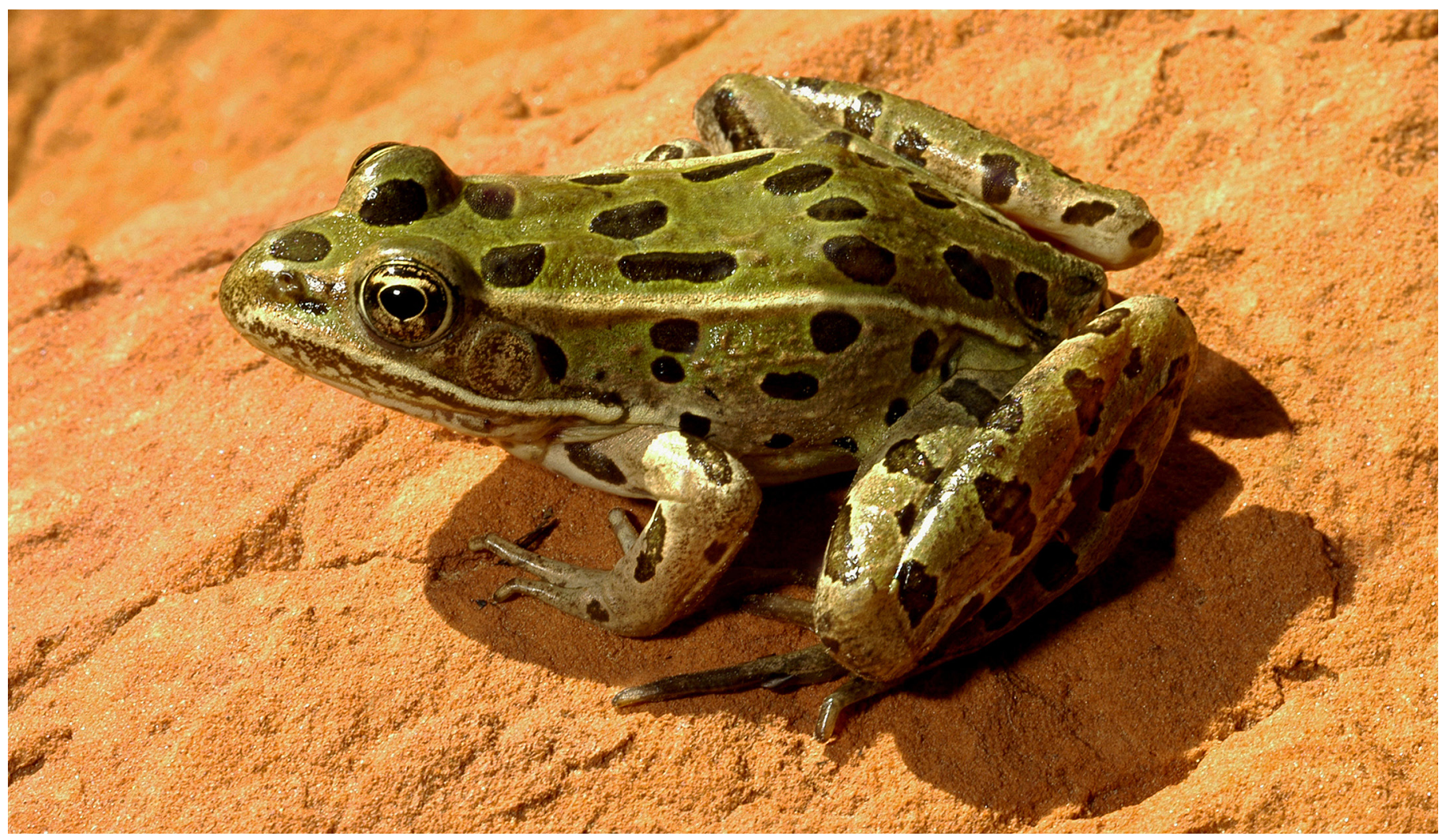

Fig. 1. Northern Leopard Frog (Lithobates pipiens). Photograph by Suzanne L. Collins (CNAH). 
documentation of the species' trends and behaviors across its distribution. To address these issues, a major objective in the current management plan for the species is that of continual research into areas including habitat use across the species' range (Environment Canada 2013). While much focus has centered on understanding factors affecting populations during summer, understanding conditions and threats related to overwintering survival also is necessary.

Lithobates pipiens (Fig. 1) is freeze intolerant and overwinters within aquatic environments (Schmid 1982). Overwintering behavior is generally considered to require a period of dormancy during the core winter months (Cunjak 1986, Klaus and Lougheed 2013, Light 1991). For the most part, L. pipiens is reported to be dormant throughout the winter; however, it is capable of movement in response to adverse environmental factors such as anoxia and water temperature decreases (Klaus and Lougheed 2013) or if it is physically disturbed (Cunjak 1986, McAdam and Nagel-Hisey 1998). Confirmation of dormancy in laboratory settings was found at $1.5^{\circ} \mathrm{C}$, where frogs became motionless and remained submerged until temperatures increased to $7^{\circ} \mathrm{C}$ (Light 1991).
Similar observations of dormancy have been reported from field observations. For example, in a non-ice covered southern Ontario river, Northern Leopard Frogs were found to be torpid with their eyes covered by their translucent nictitating membranes (Cunjak 1986). Motionless L. pipiens have also been reported from ice-free reaches of water in the Cypress Hills Interprovincial Park in Alberta and Saskatchewan (McAdam and Nagel-Hisey 1998). In both the field and laboratory studies, subjects were able to move, albeit slowly, when physically disturbed (Cunjak 1986, Light 1991, McAdam and Nagel-Hisey 1998).

A challenge to interpreting published results for management purposes is that the key terms of dormancy, hibernation, and torpor are often used interchangeably despite their different meanings. While common consensus supports some form of overwintering dormancy, anecdotal evidence suggests a lack of dormancy in these frogs. For example, winter survey data from The National Heritage Information Centre of Ontario and the Ontario Herpetofaunal Summary Atlas (http://nhic. mnr.gov.on.ca) documents observations of $L$. pipiens activity under the ice during core winter months. They also found early

Table 1. Trapping summary of live-caught Lithobates pipiens from two river systems in Saskatchewan, Canada. Water depths are those at the specific sites where traps were set and, notably for the Queen Elizabeth Power Station site, may not represent median depth of the river. Note that water depths are from the upper ice surface (when present) to the top of the benthic substrate.

Sites and trap set dates

No. days traps set Water depth (m)

No. Traps set

No. Frogs captured

Site 1 Valeport Marsh

\begin{tabular}{lcccc}
\hline 7 January 2014 & 19 & 2.3 & 15 & 2 \\
\hline 3 February 2014 & 6 & 2.3 & 10 & 0 \\
\hline
\end{tabular}

Site 2 Culverts

29 November 2013

28

1.2

10

2

Site 3 Wong's Rapids

\begin{tabular}{lcccc}
\hline 7 January 2014 & 19 & 2.9 & 10 & 0 \\
\hline 25 January 2014 & 18 & 2.9 & 6 & 0 \\
\hline 3 February 2014 & 9 & 2.9 & 10 & 2 \\
\hline
\end{tabular}

Site 4 Trestle

25 January 2014

10

4.2

10

0

Site 5 Gardiner Dam

7 December 2013

58

10

20

0

Site 6 Queen Elizabeth Power Station

10 January 2014

45

0.4

15

0 
emergence in some situations (Klaus and Lougheed 2013). Further, L. pipiens from the Cypress Hill Interprovincial Park also has been reported swimming voluntarily in mid-January (McAdam and Nagel-Hisey 1998). This provides evidence that not all individuals remain inactive for the duration of winter. While observations of winter activity are generally lacking for this species and have been attributed to environmental and physical disturbance (Klaus and Lougheed 2013), better understanding winter activity and its relation to physiological state and habitat is necessary. If the wintering requirements of the species can be defined, management plans can ensure that they not only conserve important breeding and summering habitats, but also that wintering habitats in close proximity are maintained.

The current management plan for L. pipiens in western boreal and prairie populations considers the species to hibernate over winter (Environment Canada 2013). The habitat requirements stated include aquatic environments that do not freeze to the bottom and water under $4{ }^{\circ} \mathrm{C}$ that is well oxygenated (Environment Canada 2013). A need for suitable dissolved oxygen concentrations also exists; however, the threshold for the species is not well understood (Kendell 2000). This paper describes field observations that suggest $L$. pipiens is active in mid-winter under winter ice.

\section{Materials and Methods}

We set 106 Gee minnow traps (5-cm inverted cone openings, $22.9 \mathrm{~cm}$ max width, $45 \mathrm{~cm}$ length) baited with bovine liver at six locations on the Saskatchewan and Qu'Appelle river systems in Saskatchewan, Canada during the winter of 2013-2014 (Table 1, Fig. 2). Trapping was conducted with the intention of capturing crayfish during the winter. No attempt was made to bait specifically for $L$. pipiens. The traps were set by dropped lines through augered holes in the ice until the traps reached the bottom. Trap locations included both riverine and a lake habitat. With the exception of one location (South Saskatchewan River at the Queen Elizabeth Power Plant) all the sites had seasonally permanent ice cover. Traps were left in place between six days and eight weeks. Details on the location of captured L. pipiens were recorded and specimens were released back into the water. After being checked, traps were returned to the same location. All traps were removed by the end of February 2014.

The Qu'Appelle River has relatively low flow, and between December 2013 and February 2014 the average flow rate at Lumsden (near Site 3; Wong's Rapids) was 1.6 $\mathrm{m}^{3} / \mathrm{s}$. Three of the sites, the Wong's Rapids, Trestle, and Culvert sites, are downstream of Regina. The winter flow at these sites is dominated by effluent from Regina's waste water treatment plant and augmented in variable contributions by releases from Buffalo Pound Lake. Site 1 (Valeport Marsh) was located near the south end of Last Mountain Lake and the site was not influenced by flows along the main stem

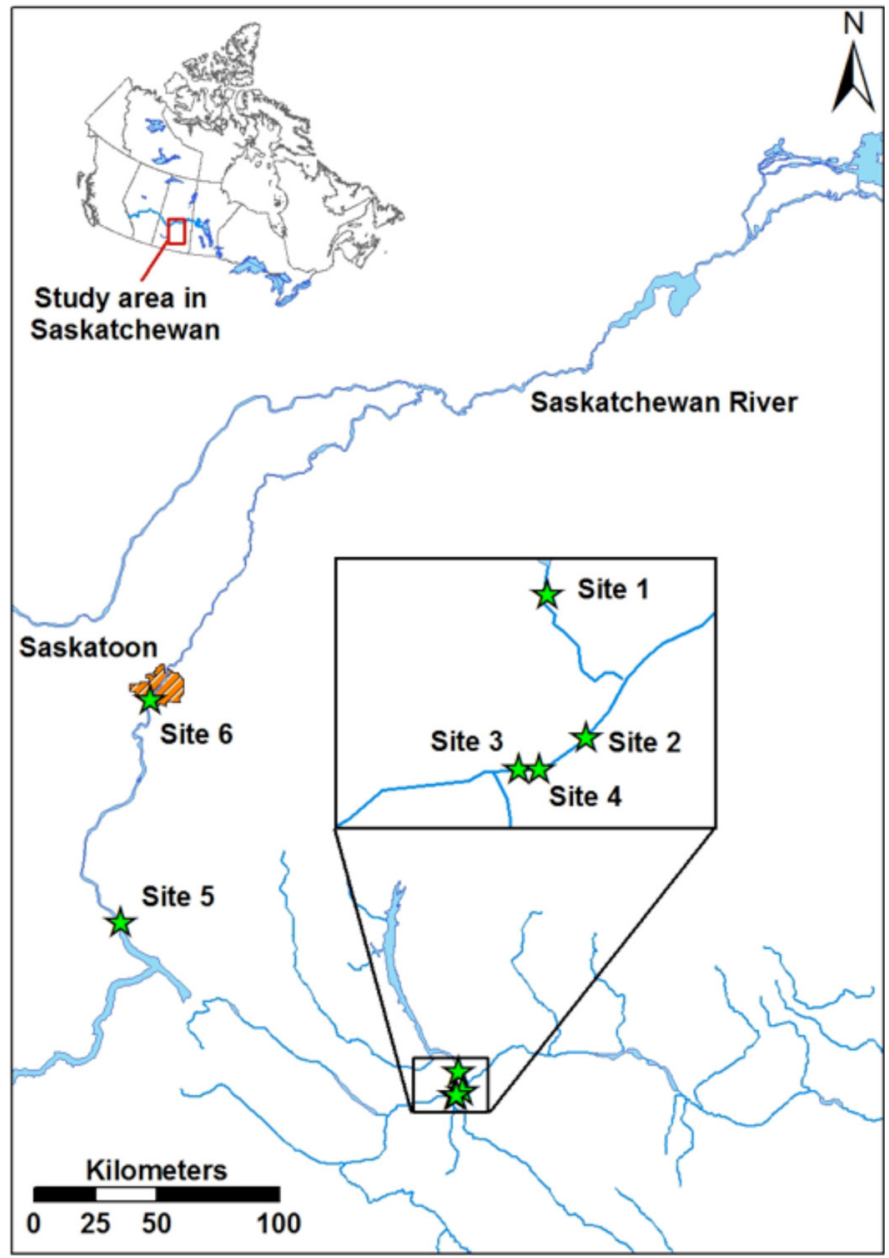

Fig. 2. Trapping locations along the Qu'Appelle and South Saskatchewan rivers, Saskatchewan, Canada. Site 1 - Valeport Marsh; Site 2 - Culverts; Site 3 - Wong's Rapids; Site 4 - Trestle; Site 5 - Gardiner Dam; and Site 6 - Queen Elizabeth Power Plant.

Qu'Appelle River during the winter of 2014. In contrast to the Qu'Appelle, the South Saskatchewan is a large river with substantially greater flows. Flow downstream of Gardiner Dam is augmented by water released from Lake Diefenbaker during the winter. From December 2013 to February 2014, the average flow of the Saskatchewan River in Saskatoon (near Site 6; Queen Elizabeth Power Station) was $300 \mathrm{~m}^{3} / \mathrm{s}$.

Water quality measurements were collected with either a YSI Quatro Pro Plus or a Hach HQ30D hand-held meter. The substrate type varied between the six trapping locations. The Qu'Appelle river sites were dominated by mud and cobble substrate, with the exception of the Trestle site that was characterized by mud only. The South Saskatchewan River sites had a boulder substrate intermingled with cobbles at the Gardiner Dam and sand at the Queen Elizabeth Power Station.

\section{Results and Discussion}

Six active $L$. pipiens were caught in the crayfish traps, with all frogs captured at sites along the Qu'Appelle River (Table 1, 


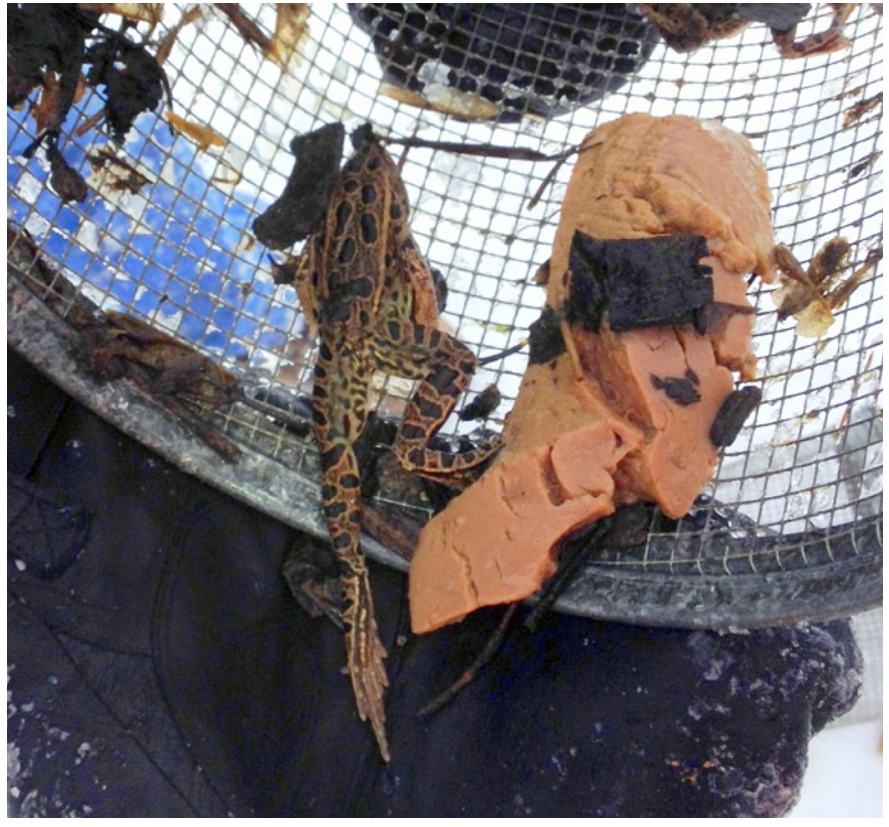

Fig. 3. Northern Leopard Frog (Lithobates pipiens) caught in a crayfish trap on 9 December 2013 at the Culvert site on the Qu'Appelle River.

Fig. 3). No signs of feeding were observed; however, frogs were moving around the traps and swam away without lethargy when released. The under-ice water temperature reached a minimum of $0{ }^{\circ} \mathrm{C}$ at all trap locations except Site 6. Site 6 (The Queen Elizabeth Power Station) is downstream of a coal and natural gas power station and had a slightly higher temperature of around $2{ }^{\circ} \mathrm{C}$ during trapping. The lowest dissolved oxygen content recorded during the trapping period was taken on the Qu'Appelle River near Site 2, where a minimum of $3.9 \mathrm{mg} / \mathrm{L}$ was recorded (Table 2). Site 4 was the only Qu'Appelle River site where frogs were not captured. This trapping location was the deepest of the four Qu'Appelle River sites at $4.2 \mathrm{~m}$ in depth, and was the only site with a mud only substrate.

Our study demonstrates that L. pipiens overwinters in the shallow Qu'Appelle River, where cobble substrate is present and that it exhibits movement behaviour under ice at low temperature $\left(0^{\circ} \mathrm{C}\right)$. Previous observations of overwintering $L$. pipiens have also reported a cobble-mud substrate (McAdam and Nagel-Hisey 1998), indicating that some form of shelter is important in their wintering habitat. This is consistent with the lack of frogs trapped at Site 4 on the Qu'Appelle River where mud dominated the substrate. Soft mud substrates can result in oxygen depletion at the substrate-water interface due to a higher percentage of organic debris (Emery et al. 1972). This low oxygen content would therefore restrict the suitability of the site for L. pipiens and may explain the absence of frogs at Site 4. Depth may also have been a limiting factor to habitat suitability at Site 4. While L. pipiens have been recorded at a depth of $3.1 \mathrm{~m}$ under ice in Ontario (Emery et al. 1972), Site 4 depth was $4.2 \mathrm{~m}$ over the winter trap- ping period and, in combination with the substrate, may have made the site unsuitable for overwintering by $L$. pipiens.

The lack of overwintering L. pipiens in the South Saskatchewan River trapping sites may be attributed to a range of variables. These include the greater size of the South Saskatchewan River, the steeper slopes to its banks, its greater flow rate, its boulder substrate, minimal marshland for breeding and summering habitat, and the locations of the traps. All of these factors are presumed to influence potential overwintering movement and suitability of the habitat for L. pipiens. Within the Qu'Appelle, the fundamental question is whether the observed winter movement provides evidence of regular activity or whether it is a temporary response to physical disturbance, changes in habitat quality, or attraction to the liver bait. Passage into traps requires active movement by frogs; they are required to move through a small entrance and down a tube of netting before entering the trap. Dormant frogs passively moving into the traps is therefore unlikely.

Disturbance factors could have resulted in temporary response movement of $L$. pipiens, including those related to trap deployment and changes in temperature or oxygen. Deployment of traps would have resulted in a localized physical disturbance and frogs in the vicinity may have responded by selectively moving into what could have been perceived as a crevice. However, we presume that movement would be away from the disturbance area and entering the small trap entrance would have been challenging for dormant individuals. This is supported by observations that disturbed $L$. pipiens in Alberta burrow farther into the substrate and away from the disturbance when touched (McAdam and Nagel-Hisey 1998). Estimates of overall frog abundance in the river or specific data on the presence of frogs within the disturbed area would provide additional data to evaluate the probability of this possible explanation.

Water temperature at Qu'Appelle sites remained at $0{ }^{\circ} \mathrm{C}$ throughout the ice-covered winter period. Dissolved oxygen concentrations remained similar from January to the end of February. Studies have examined the cost/benefit to frogs of high/low temperature under different oxygen conditions with frogs showing a preference for lower temperatures when hypoxic conditions occur (Tattersall and Boutilier 1997). However, because water temperature was $0{ }^{\circ} \mathrm{C}$, no temperature gradient was available, so this cannot explain movement of frogs in the Qu'Appelle. Furthermore, the lowest oxygen levels in the Qu'Appelle River were similar to those determined in a laboratory experiment with L. pipiens (at $3{ }^{\circ} \mathrm{C}$ ) that support normal aerobic respiration and were greater than the critical oxygen concentration that allows frogs to overwinter (Ultsch et al. 2004). These suggest that the observed frog movements were not a response to change in environmental conditions.

A final potential explanation for the trapping success of L. pipiens in the crayfish traps is that the bovine liver in the 
Table 2. Summary of water properties near trapping sites along two river systems in Saskatchewan, Canada.

\begin{tabular}{cccc} 
Sites and Dates & $\begin{array}{c}\text { Ice Cover } \\
(\mathbf{m})\end{array}$ & $\begin{array}{c}\text { Water Temperature } \\
\left({ }^{\circ} \mathrm{C}\right)\end{array}$ & $\begin{array}{c}\text { Dissolved Oxygen } \\
(\mathbf{m g} / \mathrm{L})\end{array}$ \\
\hline Qu'Appelle River & & & \\
\hline Near Site 2 & & & 11.6 \\
\hline 4 November 2013 & 0 & 0 & 3.9 \\
\hline 14 January 2014 & 0.27 & 0 & 4.2 \\
\hline 3 February 2014 & 0.46 & 0 & 3.8 \\
\hline 10 March 2014 & 0.68 & & 11.8 \\
\hline Downstream of Site 3 and 4 & & 2.0 & 4.4 \\
\hline 4 November 2013 & 0 & 0 & 5.5 \\
\hline 14 January 2014 & 0.48 & 0 & 5.2 \\
\hline 3 February 2014 & 0.60 & 0 & \\
\hline 10 March 2014 & 0.90 & & \\
\hline
\end{tabular}

South Saskatchewan River

Queen Elizabeth Power Station

4 March 2014

0

2.0

10.4

¥ $\sim 100 \mathrm{~m}$ upstream of Site 2

$\epsilon_{-250} \mathrm{~m}$ downstream of Site 4 at Lumsden, Saskatchewan

traps attracted frogs that were dormant nearby and induced the overwintering activity. Early dietary studies of L. pipiens suggest that the species is an omnivorous opportunistic feeder, feeding primarily on invertebrates and taking advantage of seasonal fluctuations in the abundance of different food sources (Linzey 1967). Consequently, frogs conceivably could be attracted to the bait in the traps. However, evidence of active frogs with empty stomachs in April collections (Linzey 1967) and signs of dormancy in laboratory experiments under a certain temperature threshold (Light 1991) suggest that baited traps alone may not induce activity in the trapped frogs if they were dormant. Further, no frogs were observed actively feeding and we found no evidence of distended stomachs from feeding in any of the trapped individuals.

Although these observations do not prove active movement behavior of $L$. pipiens under winter ice, they do demonstrate $L$. pipiens is capable of movement while overwintering, highlighting a gap in the knowledge about overwintering behavior and species requirements in the prairie region. If the species is in fact actively foraging under the ice, the assumed overwintering requirements of the species in management action plans may be leaving out important habitat requirements. This gap highlights the need for further study to better understand overwintering behavior.

\section{Acknowledgements}

This work was conducted as part of a study supported by a grant from SaskPower. We thank C. Phillips, W. Schenn, and
E. McVittie for assistance with fieldwork. Corie White and Glen McMaster provided comments on earlier drafts of this manuscript.

\section{Literature Cited}

Blaustein, A.B. and J.M. Kiesecker. 2002. Complexity in conservation: Lessons from the global decline of amphibian populations. Journal of Applied Ecology 5:597-608.

Canjak, R.A. 1986. Winter habitat of Northern Leopard Frogs, Rana pipiens, in a southern Ontario stream. Canadian Journal of Zoology 64:255-257.

Drost, C.A. and G.M. Fellers. 1996. Collapse of a regional frog fauna in the Yosemite area of the California Sierra Nevada, USA. Conservation Biology 10:414-425.

Emery, A.R., A.H. Bers, and K. Kodarra K. 1972. Under-ice observations of wintering sites of Leopard Frogs. Copeia 1972:123-126

Environment Canada. 2013. Management plan for the Northern Leopard Frog (Lithobates pipiens), western boreal/prairie populations, in Canada. Species at Risk Act management plan series. Environment Canada, Ottawa (http:// publications.gc.ca/collections/collection_2013/ec/En3-5-37-2013-eng.pdf).

Kendell, K. 2000. Investigation of Northern Leopard Frog (Rana pipiens) overwintering ecological requirements. Alberta Environment, Fisheries and Wildlife Management Division, Edmonton.

Klaus, S.P. and S.C. Lougheed. 2013. Changes in breeding phenology of eastern Ontario frogs over four decades. Ecology and Evolution 3:835-845.

Light, L.E. 1991. Habitat selection of Rana pipiens and Rana sylvatica during exposure to warm and cold temperatures. American Midland Naturalist 125:259-268.

Linzey, D.W. 1967. Food of the Leopard Frog, Rana p. pipiens, in Central New York. Herpetologica 23:11-17.

McAdam, S.H. and M. Nagel-Hisey. 1998. Winter Northern Leopard Frogs at Cypress Hills Inter-provincial Park. Blue Jay 56(3):166-168.

Pope, S.E., L. Fahrig, and H.G. Merriam. 2000. Landscape complementation and metapopulation effects on Leopard Frog populations. Ecology 81:2498-2508.

Pounds, J.A., M.R. Bustamante, L.A. Coloma, J.A. Consuegra, M.P.L. Fogden, P.N. Foster, E. La Marca, K.L. Masters, A. Merino-Viteri, R. Puschendorf, S.R. Ron, G.A. Sánchez-Azofeifa, C.J. Still, and B.E. Young. 2006. Widespread amphibian extinctions from epidemic disease driven by global 
warming. Nature 439:161-167.

Schmid, W.D. 1982. Survival of frogs in low temperature. Science 215:697-698.

Sparling, D.W., G.M. Fellers, and L.L. McConnell. 2001. Pesticides and amphibian population declines in California, USA. Environmental Toxicology and Chemistry 20:1591-1595.
Tattersall, G.J. and R.G. Boutilier. 1997. Balancing hypoxia and hypothermia in cold-submerged frogs. Journal of Experimental Biology 200:1031-1038.

Ultsch, G.R., S.A. Reese, and E.R. Steward. 2004. Physiology of hibernation in Rana pipiens: Metabolic rate, critical oxygen tension, and the effects of hypoxia on several plasma variables. Journal of Experimental Zoology 301A:169-176. 